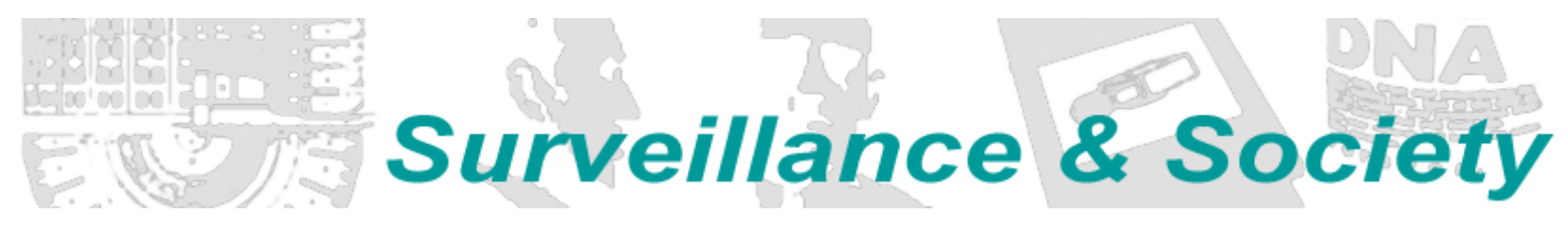

\title{
Article | Platform Policing and the Real-Time Cop
}

\section{Dean Wilson}

University of Sussex, UK

Dean.Wilson@sussex.ac.uk

\begin{abstract}
Policing, particularly in the United States, is being progressively datafied. This process has a historical trajectory that is crucial to the analysis and critique of new platform-based security architectures. Predictive policing has already attracted considerable attention, partially due to its seemingly novel fusion of predictive analytics and police work. Hyperbolic early claims - often mobilizing science fiction imagery - that the future could, in fact, be predicted, pointed towards utopic/dystopic imaginaries of seamlessly integrated control. Predictive policing is, however, increasingly only one component of cloud-based data systems that are coursing through police activity. The imaginary of these transformations can be analysed through the security imaginary of policing as a process of real-time data transmission, perpetually self-adjusting and self-augmenting through machine calculation. The historical contextualization of this imaginary suggests useful vectors of inquiry that position platform policing squarely within the mechanisms of contemporary capitalism.
\end{abstract}

\section{Introduction}

Predictive policing has become platform policing. Predictive policing —engaging predictive software to guide and distribute police patrol—is morphing into larger cloud-based modular informational policing architectures, thereby generating and incorporating diverse technologies and data streams. This short article explores how platform policing aims to leverage data to produce policing organizations that are imagined as lithe, flexible, porous, and in a state of continuous experiment. Public safety and justice clouds - which envisage instantaneous data transfer across the criminal justice system, stretching from patrol to paroleare themselves frequently envisaged as sub-components of grander digital infrastructures enveloping smart cities. In such imaginaries, the body of the officer emerges as a vital data node - the point at which data flows congeal to inform decision and action and where those actions are quantified, analyzed, fed back into data flows. The police body, thus, materializes as a pivotal target of intensive surveillance, allowing for precision management of the individual officer in real-time.

Platform policing is the term engaged here to describe the techno-organizational domestic security configurations that have been emerging since 2008. Value in this context is generated by the tempo of information streams within the policing ecosystem. As data streams within this ecosystem edge ever closer to real-time, theoretically, the proportion of surplus value produced escalates toward an apex of pure surplus value that is generated through temporal instantaneity and saturates the police ecology. Platforms generate value on multiple levels: an evident contractual level, whereby private enterprises enter into legal supplyand-maintenance agreements with police agencies; and an additional value that is generated by the data capture and processing itself, which feeds into larger cloud infrastructures and data markets. This process is subject to complex webs of regulation and exchange. However, this short article will instead be focusing on 
the police management imaginaries that - percolating down to the individual officer level-increasingly envisage the attainment of "real-time policing" as a desirable goal. Intensive datafication of the body of the individual officer is envisaged as enabling a permanently unfolding and evolving experiment, incorporating research results that are gleaned from policing strategies that evolved in the mid-to-late twentieth century, and that are perpetually striving towards "excellence." While recent research has primarily focused either on quantitative efforts to determine efficacy or the potentially deleterious impacts of an algorithmically augmented racialized and militarized policing, the focus here is on how platform policing - a development of predictive policing - functions as a mechanism of managerial surveillance and control within police organizations. This will be addressed through a historical perspective, which examines how the notion of "real-time" within policing has inextricably fused on notions of efficiency and economy. The focus here will be on the imaginaries of real-time platform policing rather than on the contingent and mutable unfolding of such imaginaries within specific contexts. This is one contribution to an ongoing discussion surrounding the digitalization of policing represented in this special issue (see Egawhary; Egbert; Gates; Linder).

Police surveillance is inherently reflexive. Historically, surveillance practices that have projected out to monitor populations have simultaneously been directed inward to exert control within police organizations (Williams 2014). Although reflexive police surveillance can be traced to the establishment of modern police institutions, it became powerfully fused with technology during the 1960s in the United States, where computerization was heralded as a powerful force that would grant police organizations the speed and flexibility to address increasingly complex and socially fractured urban environments. In 1967, the Institute of Defence Analysis - which had previously specialized in military research related to missile defence systems, nuclear war preparedness, and ballistic missile systems-published the Task Force Report on Science and Technology as part of the President's Commission on Law Enforcement and the Administration of Justice. The Task Force Report presented recommendations based on numerous current and developing technologies. Nevertheless, the strongest emphasis was on the potential of computer-based command and control systems to improve efficiencies within police organizations. The IDA applied the then ascendant concepts of systems analysis to the problem of policing. Systems analysis was an extension and elaboration of operations research and was similarly devoted to the wisdom of mathematical modelling. Systems analysis, however, incorporated a vast range of concepts drawn from fields that ranged from linear programming and uncertainty theory to social psychology and philosophy (Noble 2011: 54). The fusion of economy, efficiency, and mathematization ${ }^{1}$ was evident in the short definition of systems analysis offered in the Task Force Report, which defined it as the "use of mathematical models of real-life systems to achieve various ways of designing and using these systems to achieve specified objectives at minimum cost" (Institute of Defence Analysis 1967: 3; hereafter IDA).

Although suggestions advanced included digital fingerprinting, in-car "teleprinters," and the use of helicopters, the IDA deduced that the greatest potential for exacting efficiencies through technology and mathematical modelling resided in the domain of police command and control (IDA 1967: 21). The Report promoted the establishment of computerised command and control centres that went beyond simply "automating existing procedures" and extended to generating mathematical modelling and projections, based on "study and experiment." These, it was reasoned, would inform effective police responses to emergency situations, facilitate the development of patrol-allocation models by geography and time, optimize patrol tactics, and even facilitate calculations and projections to guide police responses to civil disorder. Mathematization and communication in as close as possible to real-time were viewed as pivotal in the Task Force Report, which remarked that "in both military and police work, rapid and complete information gathering, decision-making, and dissemination are of crucial importance" and that police response times could "often be reduced by speeding up the command and control function" (IDA 1967: 2425).

\footnotetext{
1 The term "mathematization" here follows Heidegger's conception of mathematical projection, being more than simply quantification, and rather involving a conceptual blueprint of which "mathematics" itself is only the most apparent manifestation. See Heidegger (1967).
} 
The objective of accelerating police command and control spawned the emergence of a specific research field that sought to apply mathematical models to patrol dispatch and distribution: police patrol analysis. The potential of computerization to accelerate command and control and improve efficiency had already been recognised in the early 1960s, when IBM collaborated with the Saint Louis Police Department to develop the Law Enforcement Manpower Resource Allocation System (LEMRAS) (Raub 1995: 417).

Further models were developed in the 1960s and 1970s following the Task Force Report, and frequently with funding from the US Federal Government Law Enforcement Assistance Administration. Richard Larson - an electrical engineer and researcher on the Task Force Report - sought to apply queuing theory to problems of patrol deployment. Queuing theory had been developed in the early twentieth century and had grown increasingly sophisticated over the course of the Second World War (Ceruzzi 2008: 25). Larson's "hypercube model" was elaborated into a book length study that also included simulations that allowed police managers to experiment with how different forms of police deployment-primarily the adding or subtracting of officers - would affect response times. Nevertheless, researchers developing police patrol analysis calculations became exasperated by the haphazardness and incalculability of police activity between calls for service (Larson 1972). Chaiken and Dormont, who developed the Patrol Car Allocation Model (PCAM) at RAND Corporation's New York Office, pinpointed the fundamental complication for mathematical modelling as residing in random and unquantified police activities, such as "meals, selfinitiated anticrime activities, maintenance or repair for the vehicle, special assignments by a superior officer, and authorised or unauthorised personal activities." They argued these unquantified activities constituted between 35 percent and 60 percent of all police working hours, and it was imperative they were rendered calculable for optimal functioning of the model (Chaiken and Dormont 1975: 11).

The focus on accurate mathematical modelling inherent in the application of systems analysis to policing led to both an intensified mathematization of policing and a coterminous desire for enhanced technological surveillance over the police workforce. Underpinning these desires resided an imaginary of continuous live transmission between command and officers in the field. The Task Force Report predicted that the miniaturization of radio equipment would facilitate officers being contacted and monitored, even when absent from their patrol cars. A more intensive focus, however, centred around the potential to actively monitor police vehicles in real time for the purposes of dispatch and patrol distribution. The Task Force Report suggested numerous ways this might be achieved, including police car emitters and sensors; modified radio transponder systems; medium-frequency radio-direction-finder systems; and computation and reporting systems mounted in police vehicles (IDA 1967: 25). What was termed automatic vehicle monitoring (AVM) and was initially technically imaginable but prohibitively expensive. The 20 million dollar Los Angeles Police Department electronic command and control system, developed in the 1960s and located in a bomb-proof bunker, was originally to have hosted a computerized mapping system that was capable of monitoring all patrol cars on a live display grid - a concept that was eventually jettisoned due to the enormous costs of the equipment at the time (Harring 1981: 28).

Nevertheless, experiments in AVM continued, thereby signalling an ongoing fascination with the real-time command and control of police activity. The real-time of this policing imaginary was, importantly, a computational real time. Computational real-time materialized as a priority during the Second World War, through developments in flight simulation, specifically the work of the MIT Servomechanisms Laboratory on the Airplane Stability and Control Analyser (ASCA) - an analog device that was being developed for flight simulators. The project undertook a quest to engineer a general simulator that could be programmed to mimic the characteristics of any aircraft (Edwards 1996). The objective was to reduce the cost and time involved in pilot training. How real-time was understood within policing contexts, as computerization advanced, absorbed these notions of real-time. In their 1970 study of police information systems, for example, Whisenand and Tamaru defined real-time as "the processing of information in a sufficiently rapid manner so that the results are available in time to influence the process being monitored or controlled" (1970: 27). Despite considerable expenditure on technology, personnel and research, the results of AVM experiments remained underwhelming. They did, nevertheless, indicate from survey evidence of patrol officers that they were aware that AVM intensified the capacity of their superiors "to keep track of where 
police are located, and...diminish their flexibility and force their continued movement on patrol" (Larson et al. 1977: 68). The integration of GPS data in predictive policing software, and other technologies that constitute the structures of platform policing, bring this long-cherished ambition to fruition. The tracking potentials afforded by smart city infrastructures of which they are a part extends these early imaginaries in further multivalent directions.

While police computerization continued to advance, and would expand rapidly in the 1990s, changing conceptions of police management and organization have also transformed in tandem with the economy. The systems analysis of the 1960s was applied to police organizations that had been absorbing ideas of scientific management, and reforming themselves to mirror the modern corporation, since the 1920s. Systems analysis focused on policing as Fordist production, where the product was simply a rapid response. Economic crises in the 1970s, and particularly the fiscal crisis of New York City in 1975, were part of broader transformations that included financialization and the ascendance of neoliberalism (Marrazi 2012). Management theories, interpellated by such transformations, railed against the top-down hierarchical bureaucracies of the past in favour of fast-moving rapidly transforming lithe and flexible networks that could reassemble to face the challenges of an increasingly aleatory world (Boltanski and Chiapello 2007).

Such conceptions infused the discursive world of policing through the strategy dubbed problem-oriented policing - or simply POP. First advanced by Herman Goldstein in 1979, the central precept of POP was that the police were not crime fighters, they were problem solvers. To solve problems required police organizations to become more porous, to collaborate with communities, businesses and other government agencies, and to research and analyse problems in order to solve them. Police officers were envisaged as public safety entrepreneurs, forming networks of value and collecting precious data that would aid in solving yet further problems in the future (Goldstein 1979). The implicit data thirst energized by POP initiatives became quite explicit in COMPSTAT - often, correctly, pointed to as predictive policing's immediate historic predecessor - and certainly a key historical referent for platform policing. The story of COMPSTAT has often been told from both promoters and critics, and space precludes its retelling. However, the important point is that COMPSTAT was heavily data-driven and, for present purposes, that it made precinct commanders directly responsible for quantified results, thus, creating internal competition as commanders strove to achieve optimum statistics. Moreover, the results were often graphically visualised, which — along with advances in client server technology in the 1980s-led to the widespread diffusion of computer mapping software in police departments. While retaining the flexible and porous aspects of the POP strategies (precinct commanders were given increased budgetary latitude), COMPSTAT directly installed notions of business "excellence" into the policing ecology.

Predictive policing is "the application of analytical techniques - particularly quantitative techniques - to identify likely targets for police intervention and prevent crime or solve past crimes by making statistical predictions" (Perry et al. 2013: xiii). As this article and others in this issue suggest (Gates; Linder), predictive policing refers to software programs that are now part of larger cloud-based technological and modular structures that include multiple data streams from police and other sources. The software is only one component part of platform policing. Nevertheless, there is a management aspect to the software that can be traced to the real-time fixation of the systems analysts. One evaluation did suggest that integrating GPS data would improve statistical accuracy, with the additional consequence that it would "provide information on officer activity when not on a predictive policing mission" (Mohler et al. 2015: 1410). Predictive policing software has subsequently assumed an increasingly pronounced management function within police organizations (Benbouzid 2018; Shapiro forthcoming).

How predictive policing might function for management purposes was evident in an article co-written by the Chief of the LAPD and the then Assistant Commander of the LAPD's Real-Time Analysis and Critical Response Division, developing what they branded COMPSTAT Plus. In developing COMPSTAT Plus as a managerial tool, the authors sought to emulate major retailers - primarily Target Corporation - who boast the capacity to monitor employees' performance "in real time according to a series of integrated performance metrics that measure and then display weighted data." As with POP, the authors considered 
the police organisation as an increasingly porous and collaborative enterprise, and the transformation of policing as an occasion to "expand our partnerships with our academic and business communities to continually improve our ability to forecast crime." The quest for speed, evident in the 1960s application of systems analysis, reaches its apex in a nirvana of instantaneous transmission and data feedback. As the authors exuberantly predict:

Soon we will see LAPD officers receiving information in relation to their position in time and space via Global Positioning Satellite technology and then acting on and reporting their actions as they are happening for immediate inclusion in the data set. By streamlining data entry and automating it, and then developing a more robust capability to data mine, we will move closer and closer to real time. (Bratton and Malinowski 2008: 265)

Focused not only on crime control but also on the exhaustive management of the individual officer, the authors promote partnership with "businesses at the forefront of performance management." They also recommend collecting an expansive range of digitised data on police personnel, including metrics of overtime control, sick and injured on duty time usage, morale, community satisfaction, misconduct, excessive force, officer safety, and employee wellness. Moreover, the POP concept of the patrol officer as entrepreneur and innovator is eclipsed by a conception of patrol officers as deliverers of public safety solutions - solutions computed in advance in anticipation of enactment. Gazing at near future horizons, they confidently predict that computer technology "will also likely be used to not only identify issues earlier, but to recommend interventions based on artificial intelligence support programs and functions that are selfhealing and self-correcting" (Bratton and Malinowski 2008: 265).

The emergence of predictive policing extends the legacies of 1960s systems analysis in its appeal to costeffectiveness in addition to operational efficiency. The term "predictive policing" appeared shortly after the financial crash of 2008, and early advocates stressed the capacity of predictive policing software to enable agencies "to do more with less" in a sharply contracting economy (Beck and McCue 2009). The appeal to economy and efficiency is amplified in promotional materials for platform policing. Motorola Solutions, for example, suggests that contemporary policing requires information that "is instantly available, highly relevant and easily consumed", further noting that "[c]loud deployments lower capital and operating expenses while expediting the speed of new technology adoption" (2016:2). Police agencies are implored to "offload the complexity" of deploying technology to private technology corporations, whose extension into the policing ecology reaches down to the individual officer level. This refrain resonates in many policing agencies, which in previous decades had struggled with maintaining and operating large-scale information technology systems (Manning 2001).

Through partnering with technology enterprises, platform policing promises to reform policing structures, rendering them fluidly adaptable and in a continuous state of experiment and self-correction. The realization of this police imaginary requires that they have an integral capacity for self-evolution. As Brian Massumi remarks in relation to conceptions of network-centric warfare (which themselves mirror contemporary business theories):

The evolutionary feedback must operate in as close to real-time as possible, the up and down feedback occurring with such lightning speed as to make the military hierarchy the topological equivalent of the horizontality of the network. (2015: 96)

Contemporary corporate-police imaginaries envisage this model transposed onto the policing context as an incessant and instantaneous transmission enfolds the body of the patrol officer. Motorola Solutions, for example, has developed a sensorised patrol uniform that integrates display smart glasses, biometric health monitoring, gun holster sensors, and environmental sensors. This "future-ready" system, the brochure suggests, "empowers police officers to respond and change the trajectory of a single moment while still in that moment" (Motorola Solutions 2015: 7). 
Increasingly interpellated by the value-seeking mechanisms of surveillance capitalism, police organizations are reimagined both as consumers of technology and as producers of surplus value. The real-time cop becomes flexible, accessible, and seemingly autonomous, while being tightly controlled through data streams. Recent market branding of platform policing as "precision policing" highlights an imaginary of constantly mutable and precisely targeted policing decisions (Bratton and Murd 2018). While various budget costs related to platform policing are direct contractual costs, police knowledge-increasingly informationalized - also becomes an additional source of value. Police knowledge itself becomes a form of economic power. Instantaneous transmission is therefore central, through a desire for rapid information flows that operate "at the speed of light precisely because events and information are merchandise whose value is a function of time" (Stiegler 2009: 112). Police knowledge is further commoditized as digitalized police actions are recorded and perpetually reticulated through a process of constant performance management and training. The 2017 Law Enforcement Technology Report of Taser International envisages officers in a perpetual condition of reflexive learning, with officers reviewing their own interactions, and drawing direct comparisons to Facebook's personalised "year in review." Imagining an officer viewing their individualized bodycam footage during downtime, the report suggests:

You could watch it and say, Uh, you know what? I should have had more patience there. If I had spent five more minutes with this person, I could have talked them down. I could have deescalated the situation better by watching myself. (2017: 31)

Flexible, porous, and no longer public, but not entirely private either, the promoters of platform policing imagine it as an ultra-solution to the multifarious problems of economy, public trust, brutality, and violence - and demoralised workforces - that beset contemporary policing in the United States and elsewhere. What can be stated is that policing - which has historically mimicked business practices but has struggled with notions of what its product was and how "value" could be assessed - is now a key consumer within the economy. Moreover, policing is an active generator of surplus value through datafication. While questions of which algorithms operate, and how their parameters might be more equitably set, are important, this wider absorption of policing into the economy needs to be acknowledged. Where does the value extracted from the real-time cop go? And what kind of policing, and in whose interests, does the real-time cop perform?

\section{References}

Beck, Charlie, and Colleen McCue. 2009. Predictive Policing: What Can We Learn from Wal-Mart and Amazon about Fighting Crime in a Recession? The Police Chief 76, www.policechiefmagazine.org [accessed November 16, 2015].

Benbouzid, Bilel. 2018. Quand prédire, c'est gerer. La police prédictive aux Etats-Unis. Reseaux 5 (211): 221-255.

Boltanski, Luc, and Evé Chiapello. 2007. The New Spirit of Capitalism, translated by Gregory Elliott. London: Verso.

Bratton, William J., and Jon Murad. 2018. Precision Policing: Data, Discretion, and Community Outreach Can Ensure a New Era of Public Safety. City Journal, September, https://www.city-journal.org/html/precision-policing-16033.html [accessed September 30, 2018].

Bratton, William J., and Sean W. Malinowski. 2008. Police Performance Management in Practice: Taking COMPSTAT to the Next Level. Policing: A Journal of Policy and Practice 2 (3): 259-265.

Ceruzzi, Paul. 2008. Internet Alley: High Technology in Tyson's Corner, 1945-2000. Cambridge, MA: MIT Press.

Chaiken, Jan M., and Dormont, Peter. 1975. Patrol Car Allocation Model: Executive Summary. New York: New York City Rand Institute.

Edwards, Paul. 1996. The Closed World: Computers and the Politics of Discourse in Cold War America. Cambridge, MA: MIT Press.

Goldstein, Herman. 1979. Improving Policing: A Problem-Oriented Approach. Crime and Delinquency 25 (2): $236-258$.

Harring, Sid. 1981. Taylorization of Police Work: Prospects for the 1980s. Insurgent Sociologist 11 (1): 25-32.

Heidegger, Martin. 1967. What is a Thing? translated by W. B. Barton and Vera Deutsch. South Bend, IN: Gateway Editions.

Institute of Defence Analysis. 1967. Task Force Report: Science and Technology. Washington, DC: US Government Printing Office.

Larson, Richard C. 1972. Urban Police Patrol Analysis. Cambridge, MA: MIT Press.

Larson, Richard, Kent Colton, and Gilbert Larson. 1977. Evaluating a Police-Implemented AVM System: The St Louis Experience (Phase 1). IEEE Transactions on Vehicular Technology 26 (1): 60-70.

Manning, Peter K. 2001. Technology's Ways: Information Technology, Crime Analysis and the Rationalization of Policing. Criminal Justice 1 (1): 83-103. 
Marazzi, Christian. 2012. Capital and Language: From the New Economy to the War Economy. South Pasadena, CA: Semiotext(e).

Massumi, Brian. 2015. Ontopower: War, Powers, and the State of Perception. Durham, NC: Duke University Press.

Mohler, G. O., M.B. Short, Sean W. Malinowski, Mark Johnson, G.E. Tita, Andrea L. Bertozzi, Andrea, and P. J. Brantingham. 2015. Randomized Controlled Field Trials of Predictive Policing. Journal of the American Statistical Association 110 (512): 1399-1411.

Motorola Solutions. 2015. Communication Systems Stop Crime in Its Tracks: Real Time Intelligence Takes Police Beyond Responding, To Prediction and Prevention. Schaumburg, IL: Motorola Solutions.

Motorola Solutions. 2016. Deploying Smart Public Safety Solutions in the Cloud. Schaumburg, IL: Motorola Solutions.

Noble, David. 2011. Forces of Production: A Social History of Industrial Automation. Brunswick, NJ: Transaction Publishers.

Perry, Walter L., Brian McInnes, Carter C. Price, Susan C. Smith, and John S. Hollywood. 2013. Predictive Policing: The Role of Crime Forecasting in Law Enforcement. Santa Monica, CA: RAND Corporation.

Raub, Richard. 1995. Manpower Allocation. In The Encyclopedia of Police Science, edited by William Bailey, 416-419. New York: Garland Publishing.

Shapiro, Aaron. Forthcoming. Predictive Policing for Reform? Indeterminancy and Intervention in Big Data Policing. Surveillance \& Society.

Stiegler, Bernard. 2009. Technics and Time 2: Disorientation. Stanford, CA: Stanford University Press.

TASER International, Inc. 2017. 2017 Law Enforcement Technology Report. Scotsdale, AZ: TASER International, Inc.

Whisenand, Paul, and Tug Tamaru, Tug. 1970. Automated Police Information Systems. New York: Wiley.

Williams, Chris. 2014. Police Control Systems in Britain 1775-1975. From Parish Constable to National Computer. Manchester, UK: Manchester University Press. 